\title{
Per-Partum Anaemia and Missed Post-Partum Haemorrhage in Low Resources Settings
}

\author{
Valere Salomon Mve Koh ${ }^{1,2 *}$, Claude C. Noa Ndoa ${ }^{1,3}$, Julius Dohbit Sama ${ }^{1,4}$, Raoul Tefee II ${ }^{1}$, \\ Philipe Nana Njotang1,5 \\ ${ }^{1}$ University of Yaoundé I, Yaoundé, Cameroon \\ ${ }^{2}$ University Teaching Hospital of Yaoundé, Yaoundé, Cameroon \\ ${ }^{3}$ Centre Hospitalier de Recherche et d'Application en Chirurgie Endoscopique et Reproduction Humaine (CHRACERH), \\ Yaoundé, Cameroon \\ ${ }^{4}$ Gynaeco-Obstetric and Paediatric Hospital of Yaoundé, Yaoundé, Cameroon \\ ${ }^{5}$ Central Hospital of Yaoundé, Yaoundé, Cameroon \\ Email: *vmvekoh@yahoo.com, claude_noa@yahoo.co.uk, dohbit@yahoo.com, \\ raoulteffee2marcy@yahoo.com, njotangnanaphilip@yahoo.com
}

How to cite this paper: Mve Koh, V.S., Noa Ndoa, C.C., Dohbit Sama, J., Tefee II, R. and Nana Njotang, P. (2018) Per-Partum Anaemia and Missed Post-Partum Haemorrhage in Low Resources Settings. Open Journal of Obstetrics and Gynecology, 8, 1557-1568.

https://doi.org/10.4236/ojog.2018.814156

Received: October 18, 2018

Accepted: December 24, 2018

Published: December 27, 2018

Copyright $\odot 2018$ by authors and Scientific Research Publishing Inc. This work is licensed under the Creative Commons Attribution International License (CC BY 4.0).

http://creativecommons.org/licenses/by/4.0/

(c) (i) Open Access

\begin{abstract}
Background: Post-partum haemorrhage is the leading cause of maternal death throughout the world, and anaemia is one of its indirect causes. Anaemia during labour increases the risk of $\mathrm{PPH}$ and may lead to maternal mortality even after moderate $\mathrm{PPH}$. Undiagnosed $\mathrm{PPH}$ and post-partum anaemia increases the risk of late maternal death in the community. The aim of this study was to assess the prevalence of anaemia on admission for labour, the occult early post-partum haemorrhage and the magnitude of post-partum anaemia in a low resource setting. Methods: This was a longitudinal study. We included pregnant women in labour. Haemoglobin concentration was measured on admission (H0), then 24 hours (H24) and 48 (H48) hours later. The post-partum blood loss was estimated by delta haemoglobin, using the criteria of M. Driessen et al. Results: We recruited 245 pregnant women. The mean age was $27.0 \pm 6.0$ years. The mean hemoglobin concentration was 11.7 $\pm 1.9 \mathrm{~g} / \mathrm{dl}$, the frequency of anaemia was $30.6 \%$ and was related to ethnicity $(P=0.042)$ gestational age $(\mathrm{p}<0.001)$ marital status $(\mathrm{p}=0.014)$ and the inter pregnancy time space $(\mathrm{p}=0.001)$. Twenty-two-point two percent had post-partum haemorrhage among which $40 \%$ were undiagnosed. The mean blood loss was $375 \mathrm{ml}$ and post-partum anaemia rate was $44.5 \%$. Conclusion: Anaemia on admission was related to socio-demographic characteristics. The frequencies of anaemia during labour, missed PPH and undiagnosed post-partum anaemia were high. Haemoglobin concentration on admission for labour and after delivery, reliable method to assess PPH should be mandatory, to better identify per and post-partum anemia, and the management of $\mathrm{PPH}$, in low income environments.
\end{abstract}




\section{Keywords}

Haemoglobinometer, Per-Partum, Anaemia

\section{Introduction}

The pregnancy process brings many physiological changes to the pregnant women amongst which hemodilution due to plasma volume increase and lesser red blood count increase causing physiologic anaemia [1]. Anemia defined as hemoglobin concentration $<11 \mathrm{~g} / \mathrm{dl}$, is also a nutritional deficiency affecting close to 33 million pregnant women worldwide, both in developed and developing countries, and Africa has the second highest anaemia prevalence and the highest prevalence of severe anaemia both in pregnancy [2]. Cameroon is a sub-Saharan central African developing country in the Gulf of Guinea, with 25 million inhabitants. The climate is a tropical and malaria, an indirect cause of maternal mortality [3] is endemic throughout the whole country and is another leading cause of anaemia during pregnancy by haemolysis occurring during the process of this infection and adverse effect on iron storage [4] [5]. Nearly 50\% of Cameroonian pregnant women presented anaemia during pregnancy in 2011 and the level of public health significance was severe [2]. Anaemia represents $50 \%$ of indirect causes of severe maternal outcome defined as a woman having had a maternal death or maternal near miss [3], underlying 115,000 maternal death and 591,000 perinatal deaths in the world per year [6]. Anaemia during pregnancy is also related to poor perinatal outcome increasing the risk of preterm birth, low birth weight, and small gestational age when occurring in the first trimester and the risk of low birth weight in the third trimester [7].

There is always some blood loss in every delivery process, and therefore a worsening potential of preexisting anemia after delivery during postpartum blood loss. Anaemia during labour even increases the risk of postpartum haemorrhage (PPH) [8], the first direct cause of maternal death throughout the world [9], and may lead to maternal mortality even following a moderate $\mathrm{PPH}$.

Visual estimation is still the most commonly used postpartum blood loss assessment [10], but underestimation represents $25 \%$ - 50\% when visual assessment is compared to photo spectrometry [11]. Visual estimation was even recently found to be inaccurate and requested to be withdrawn from standard obstetric practice [12]. The incidence of undiagnosed abnormal post-partum blood loss measured by collector bag versus peripartum haemoglobin concentration assessment was still $11 \%$ in a recent study in France, a developed country [13]. Postpartum anaemia is also a worldwide issue and its prevalence is highest in developing countries [14], post-partum severe anaemia acute or chronic can triple maternal mortality in the post-partum [15].

In Cameroon, a country with a maternal mortality rate 3.5 times higher than the recommended maximum of 140 [16], there's no assessment of hemoglobin 
concentration on admission before and after delivery. Undiagnosed $\mathrm{PPH}$ due to visual estimation of blood loss and post-partum anaemia cases may be discharged, with potential late maternal death in the community.

The aim of this study was to analyse the prevalence of anaemia before and after labour, in order to assess clinically occult early post-partum haemorrhage and the magnitude of post-partum anaemia, for a better management of maternal perinatal anaemia in low resource setting.

\section{Patients and Methods}

This was a longitudinal study, conducted from February $1^{\text {st }}$ to April $30^{\text {th }} 2017$, in three university teaching hospitals affiliated to the Faculty of Medicine and Biomedical Sciences of the University of Yaoundé I, Cameroon, namely, the University Teaching Hospital, the Central Hospital and the Gynaeco-Obstetric and Paediatric Hospital, all in the capital city and representing the top of the health system pyramid in Cameroon. The study population was women delivering in the maternities of these three hospitals.

This study received the approval of the ethical committee of the University of Yaoundé I, and the authorizations of the directors of the three-university teaching hospital. The follow up of pregnant women is carried out by specialists in obstetrics and gynaecology, some of them university lecturers, offering complete obstetric care. This study was conducted.

An informed written consent was signed by every participant, after due explanations on the risks and benefits of this study, which didn't interfere with the appropriate management of the labour process. We included pregnant women at a gestational age of at least 28 completed weeks, admitted in labour in the maternities of these hospitals. Women with a past history of antenatal haemorrhage, who delivered by caesarean section, those with multiple pregnancy, homozygous sickle cell disease, or who received any blood product transfusion prior to admission were excluded.

The procedure included, capillary haemoglobin $(\mathrm{Hb})$ concentration of blood from fingertip, collected after due asepsis, measured by HemoCue $\mathrm{Hb} 301$ hemoglobinometer $\left(\right.$ Cera chek ${ }^{\circledR}$ ) on admission called hour zero (H0). The data were read after 6 seconds as recommended by HemoCue Hb 301 hemoglobinometer user manual. Women were sampled on admission, at 24 hours and 48 hours post-admission counted in minutes, called H24 and H48. Anaemia was defined according to Grewal and Levy criteria corresponding to Cameroonian standards as haemoglobin concentration $<10 \mathrm{~g} / \mathrm{dl}$. Delta haemoglobin was used to calculate post-partum blood loss according to $M$ Driessen. The degree of anaemia according to haemoglobin concentration was defined as follows:

Blood loss according to M Driessen's criteria: [17]

Data were processed using the SPSS 21.0.X2 for quantitative data and Fisher exact test for dichotomic data. $\mathrm{P} \leq 0.05$ was the threshold of statistical significance. 


\section{Results}

We included 245 cases, $49 \%(\mathrm{n}=120)$ from the Central Hospital, $41 \%(\mathrm{n}=102)$ from the Gynaeco-Obstetric and Paediatric Hospital and 9.4\% $(n=23)$ from the University Teaching Hospital. The prevalence of anaemia on admission in labour room was $30.2 \%(75 / 245)$. The mean age was $27.0 \pm 6.0$ years the extremes from 17 to 42 years.

Anaemia rate on admission was $30.6 \%$ amongst which 25.3 was mild, there was no severe anaemia. The mean $\mathrm{Hb}$ level was $11.7 \pm 1.9 \mathrm{~g} / \mathrm{dl}$ (minimum 6.5 and maximum $15.8 \mathrm{~g} / \mathrm{dl}$ ).

After delivery, the frequency of anaemia increased to $46.6 \%$ including $1.2 \%$ severe anaemia from zero on admission. The mean $\mathrm{PP} \mathrm{Hb}$ concentration was $10.2 \pm 1.9 \mathrm{~g} / \mathrm{dl}(5.3-15.0 \mathrm{~g} / \mathrm{dl})$.

Early post-partum haemorrhage frequency was $22.5 \%, 3.2 \%$ were severe. The mean blood loss was $1.5 \mathrm{~g} / \mathrm{dl}(375 \mathrm{ml})$.

Up to $40 \%$ of the 55 post-partum haemorrhage were undiagnosed.

\section{Discussion}

This longitudinal study had some limits due to the short period of enrolment and its prospective and multicentric approach.

\subsection{Prevalence of Anaemia on Admission}

Our frequency of anaemia on admission was $30.6 \%$ (75/245) (Table 3). It was higher in Thailand (41\%) on admission for labour, although only HIV positive women were included [18], the HIV status being one of the main causes of anaemia as shown by other studies [19] [20]. More than $90 \%$ were anemic on admission for labour in a study in India and it was related to number of antenatal care (ANC), education level and lack of folic acid intake [21].

In China, $\mathrm{Ma}$ in a randomized study analysing 6.413 pregnant women sampled within two weeks before delivery, found a prevalence of anaemia defined as haemoglobin concentration $<11 \mathrm{~g} / \mathrm{dl}$ varying from $48.1 \%$ to $70.5 \%$ for an average of 58.6\%. They suspected nutritional status [22]. Chen had shown indeed that, nutrient supplementation during pregnancy in China was not popular, with one third of them who never used any supplementation and the recommendations were poorly implemented [23]. It was lower than the prevalence of iron deficiency anaemia in the third trimester in one of the study sites of our study in 2016 [24], probably due to optimized intake of iron and the management of underlying diseases like malaria at the end of third trimester of pregnancy as it is the case in our study, as compared to the whole third trimester considered in that one. Fikir also identified Intestinal helminth infection as a cause of anaemia [25].

Lower frequencies of anaemia in the third trimester of pregnancy were found in Turkey (19.8\%), this was explained by the routine prescription of iron tablet [26]. This lower frequency of anaemia compared to the developing countries mentioned previously is probably explained by Cameroon's lower anaemia di- 
agnostic criteria $(\mathrm{Hb}<10 \mathrm{~g})$ and its mandatory routine iron intake during the whole pregnancy. Iron deficiency can concern up to $90 \%$ of anaemia cases during pregnancy [27]. Other reasons may be the countrywide national policy of the prevention of malaria, another tropical cause of anaemia in pregnancy, by in-situ administration of free sulfadoxine-pyrimethamine tablets during pregnancy and a nationwide distribution of free mosquito nets.

However, after several months of pregnancy and probably poor follow up, one third still presented with mild to moderate anaemia on admission for labour, an avoidable indirect cause of maternal death, with little time needed to easily improve the haemoglobin concentration, in a low resource setting (Table 4). Shilpa et al. found a rate of $5.6 \%$ of severe anaemia, defined as $\mathrm{Hb}$ concentration $<7$ $\mathrm{mg} / \mathrm{dl}$, out of 3963 deliveries on a three-year period [28]. WHO advocates the identification of populations at greatest risk of anaemia especially when resources are limited [29].

Anaemia on admission in our study was related to marital status, short inter-pregnancy intervals, and gestational age, (Table 1 and Table 2) as found in previous studies [7] [30]. We found some influence of ethnicity concerning anaemia on admission, (Table 2) which need to be confirmed by case control studies. However, some cultural and ethnic behaviours like geophagia have been shown to reduce iron absorption [31]. We didn't notice a correlation with parity, (Table 3) probably because of our cut-off method which was $\leq 5$ instead of analysing one parity after another as it has been done in previous studies.

\subsection{Post-Partum Hemorrhage}

Only $53.4 \%$ still had normal haemoglobin concentration 24 hours post-partum (Table 4) compared to $69.4 \%$ on admission (Table 3) and PPH occurred in $22.5 \%$ of the study population (Table 5), higher than the $9 \%$ in rural Uganda, using a calibrated under-buttocks VBRASSS drape in women who had vaginal birth [20], and the global rate of 6\% [32]. The difference of method of evaluation cannot explain this gap.

Table 1 . Hb concentration according to sociodemographic data.

\begin{tabular}{cccccc}
\hline Variables & \multicolumn{2}{c}{ Hb concentration (g/dl) } & $\begin{array}{c}\text { Total } \\
\text { N (\%) }\end{array}$ & $\begin{array}{c}\text { Odds Ratio } \\
(95 \% \mathrm{CI})\end{array}$ & P value \\
\cline { 2 - 3 } Ethnicity & $<10 \mathrm{~g} \mathrm{~N}(\%)$ & $>10 \mathrm{~g} \mathrm{~N}(\%)$ & & & \\
Beti & $42(40.8)$ & $49(34.5)$ & $91(37.1)$ & & \\
Bamileke & $29(28.2)$ & $63(44.4)$ & $92(37.5)$ & $0.54(0.29-0.98)$ & 0.042 \\
Bamoun & $12(11.7)$ & $10(7.0)$ & $22(8.9)$ & & \\
Other ethnicities & $20(19.4)$ & $20(14.1)$ & $40(16.3)$ & & \\
Marital status & & & & & \\
Married & $47(44.6)$ & $60(42.3)$ & $107(43.6)$ & & \\
Divorced & $2(1.9)$ & $2(1.4)$ & $4(1.6)$ & $0.45(0.27-0.87)$ & \\
Single & $45(43.7)$ & $55(38.7)$ & $100(40.8)$ & & \\
Co-habiting & $9(8.7)$ & $25(17.6)$ & $34(13.8)$ & & \\
\hline
\end{tabular}


Table 2. Obstetrical data on admission according to $\mathrm{Hb}$ concentration.

\begin{tabular}{|c|c|c|c|c|c|}
\hline \multirow{2}{*}{ Variables } & \multicolumn{2}{|c|}{$\mathrm{Hb}$ level } & \multirow{2}{*}{ Total N (\%) } & \multirow{2}{*}{ Odds Ratio (95\% CI) } & \multirow{2}{*}{$P$ value } \\
\hline & $<10 \mathrm{~g} / \mathrm{dl} \mathrm{N}(\%)$ & $\geq 10 \mathrm{~g} / \mathrm{dl} \mathrm{N}(\%)$ & & & \\
\hline \multicolumn{6}{|l|}{ Parity } \\
\hline$\leq 5$ & $73(44.2)$ & $94(55.8)$ & $167(68.1)$ & $1.24(0.71-2.15)$ & 0.43 \\
\hline$>5$ & $30(38.5)$ & $48(61.5)$ & $78(31.8)$ & & \\
\hline \multicolumn{6}{|c|}{ Gestational age (weeks) } \\
\hline$<37$ & $37(45.6)$ & $44(54.3)$ & $81(33.0)$ & $1.25(0.72-2.14)$ & $<0.001$ \\
\hline$\geq 37$ & $66(40.2)$ & $98(59.8)$ & $273(67.0)$ & & \\
\hline \multicolumn{6}{|c|}{ Inter-pregnancy interval (years) } \\
\hline$\leq 2$ & $31(26.7)$ & $85(73.3)$ & $116(47.3)$ & $3.2(1.87-5.54)$ & 0.0001 \\
\hline$>2$ & $67(54.0)$ & $60(47.0)$ & $127(52.6)$ & & \\
\hline \multicolumn{6}{|c|}{ ANC (number) } \\
\hline$\leq 4$ & $22(44.9)$ & $27(55.1)$ & $49(20.0)$ & $1.15(0.61-2.17)$ & 0.79 \\
\hline$>4$ & $81(41.3)$ & $115(58.7)$ & $196(80.0)$ & & \\
\hline
\end{tabular}

ANC: antenatal consultation.

Table 3. Hb concentration on admission (H0).

\begin{tabular}{ccc}
\hline $\mathrm{Hb}(\mathrm{g} / \mathrm{dl})$ & $\mathbf{N}$ & $(\%)$ \\
\hline $10 \mathrm{~g} / \mathrm{dl}$ & 170 & 69.4 \\
{$[8-10[\mathrm{~g} / \mathrm{dl}$} & 62 & 25.3 \\
{$[6-8[\mathrm{~g} / \mathrm{dl}$} & 13 & 5.3 \\
$<6 \mathrm{~g} / \mathrm{dl}$ & 0 & 0 \\
Total & 245 & 100
\end{tabular}

H0: hour of admission.

Table 4. Early post-partum Hb concentration evolution (H0 minus H24).

\begin{tabular}{cccc}
\hline Hct $(\%)$ & $\mathrm{Hb}(\mathrm{g} / \mathrm{dl})$ & $\mathbf{N}=245$ & $(\%)$ \\
\hline$>30 \%$ & $>10 \mathrm{~g} / \mathrm{dl}$ & 131 & 53.4 \\
{$[24 \%-30 \%[$} & {$[8-10[\mathrm{~g} / \mathrm{dl}$} & 92 & 37.6 \\
{$[18 \%-24 \%[$} & {$[6-8[\mathrm{~g} / \mathrm{dl}$} & 19 & 7.8 \\
$<18 \%$ & $<6 \mathrm{~g} / \mathrm{dl}$ & 3 & 1.2 \\
\hline
\end{tabular}

H24:24 hours post admission.

Table 5. Measurement of early post-partum haemorrhage.

\begin{tabular}{cccc}
\hline$\Delta \mathrm{Hb}(\mathrm{g} / \mathrm{dl})$ & Value in $\mathrm{ml}$ & $\mathrm{N}=245$ & $(\%)$ \\
\hline$<1$ & $<250$ & 10 & 4.08 \\
{$[1-2[$} & {$[250-500[$} & 180 & 73.4 \\
{$[2-3[$} & {$[500-750[$} & 36 & 14.6 \\
{$[3-4[$} & {$[750-1000[$} & 11 & 4.4 \\
$>4$ & $>1000$ & 8 & 3.2 \\
\hline
\end{tabular}


One of the reasons may be the high rate of anaemia on admission. Anaemia during pregnancy is indeed a predicting factor of $\mathrm{PPH}$ as there is a correlation between low Hb levels and blood loss [8] [33], thus emphasizing the need for an efficient management of anaemia before the onset of labour.

Delivery assisted by qualified health care provider, which was supposed to be the case in these University Teaching Hospitals, is one of the pillars of the fight against maternal morbidity and mortality. Moreover, the active management of the third stage of labour has been adopted in those maternities for years, making this high frequency of $\mathrm{PPH}$ quite unexpected. Lack of motivation and regular trainings, frequent replacement of skilled personnel by new comers, lack of appropriate medical material, and ignorance of patients are some reasons among others of below standard practice in poor environment. [34].

Concerning the human factor, shown by the $3.2 \%$ of severe PPH (Table 5), which should not happen within a first category medical centre providing full obstetrical emergency care, normal vaginal delivery, condition of enrolment in this study, is usually conducted by nurses, with fewer midwives due to the closure for more than 15 years of midwifery schools in Cameroon. Gynaecologists and obstetricians are called upon when a patient shows or complains about early signs of pre-shock, usually after blood loss of $1000 \mathrm{ml}$ and above.

Lack of motivation and regular trainings, frequent replacement of skilled personnel by new comers, lack of appropriate medical material, and ignorance of patients are some reasons among others of below standard practice in such a poor environment [24]. Such factors were not investigated in this study.

In the United States, the Association of Women's Health, Obstetric and Neonatal Nurses (AWHONN) recommends that blood loss be formally measured by calibrated under-buttocks bag after every birth [35]. Its use is mandatory in Japan [36]. It is applied at the end of third stage of labour, with an alert line when blood loss reaches $350 \mathrm{ml}$, timing the moment when the nurse should call for better expertise, to reduce the frequency and the magnitude of blood loss. We think that it should be systematically adopted, to improve the recognition and early management of post-partum blood loss in low income environment and as such avoid severe PPH. Spontaneous delivery with episiotomy/perineal tear and forceps delivery can also cause a greater blood loss [37]. These relationships were not investigated in this work.

\subsection{Missed Post-Partum Hemorrhage}

Nearly half of PPH went undiagnosed, (Table 6) due to non-routine evaluation of blood count before and after delivery as it is the case in developed countries [38]. An unreliable blood loss estimation can delay the recognition and management of $\mathrm{PPH}$, moreover, even ignored and discharged mild or moderate anaemia may worsen during late post-partum period in the community as prolonged breastfeeding has been shown to reduce iron concentration [39].

Post-partum anaemia is an important and yet partly unrecognized problem 
even in developed countries [40]. It remains a major concern in developing countries with a prevalence of $50 \%$ to $95 \%$ [41], but was lower (30\%) in the United Kingdom [42]. Post-partum severe anaemia acute or chronic can almost triple maternal mortality during pregnancy and in the post-partum [15]. Post-partum anaemia on day 2 in our study concerned 45.5\%, (Table 7) twice higher than a German study concerning 43,807 deliveries, where it was mostly related to delivery blood loss [40], or the $26.5 \%$ found in India [43].

This may be attributed to higher frequency of anaemia on admission and $\mathrm{PPH}$, with chilling potential postpartum complications as the anaemic mother returns to the community, without close care as compared to the antenatal follow up period, since most of the study population might have gone undiagnosed thanks to this study, as routine assessment of the $\mathrm{Hb}$ profile is only done when patients present clinical signs of anaemia, and iron intake is yet to be a mandatory recommendation in our country. Screening or not in the post-partum of nursing mothers remains a debate [44]. Charrafine has shown indeed the advantage of blood count during the post-partum [38], moreover as mentioned above, breastfeeding can increase maternal anaemic status, as Increased total breastfeeding duration, a culture in Africa, is associated with decreased iron stores [39].

\section{Conclusion}

Anaemia during labour was related to socio-demographic characteristics. The frequencies of anaemia during labour, missed $\mathrm{PPH}$ and undiagnosed post-partum anaemia were high. Screening of $\mathrm{Hb}$ concentration on admission for labour and after delivery, the use of reliable blood assessment method like calibrated

Table 6. Diagnosed and missed PPH.

\begin{tabular}{ccc}
\hline Post-partum hemorrhage & $\mathrm{n}$ & $(\%)$ \\
\hline Clinically diagnosed PPH \& Management & 33 & 60 \\
Missed (Undiagnosed) PPH & 22 & 40 \\
Total & 55 & 100 \\
\hline
\end{tabular}

PPH: post-partum haemorrhage.

Table 7. Post-partum anaemia after 48 hours post admission.

\begin{tabular}{ccc}
\hline $\mathrm{Hb}(\mathrm{g} / \mathrm{dl})$ & $\mathrm{N}$ & $(\%)$ \\
\hline$>10 \mathrm{~g} / \mathrm{dl}$ & 136 & 55.5 \\
{$\left[8-10\left[\mathrm{~g} / \mathrm{dl}^{*}\right.\right.$} & $90^{*}$ & $36.7^{*}$ \\
{$\left[6-8\left[\mathrm{~g} / \mathrm{dl}^{*}\right.\right.$} & $17^{*}$ & $6.9^{*}$ \\
$<6 \mathrm{~g} / \mathrm{dl}{ }^{* *}$ & $2^{* *}$ & $0.8^{* *}$ \\
Total & 245 & 100 \\
\hline
\end{tabular}

The frequency of anaemia on day 2 postpartum was $44.5 \%$. *all cases of light to moderate anaemia were discharged on day 2 with oral iron tablets; ${ }^{*}$ The two cases were yet to receive the prescribed full blood transfusion two days after delivery. 
under-buttocks bag after every birth and post-partum anaemia assessment can improve the identification of cases of anaemia before discharge to the community and should be a recommendation in low income environment like ours.

\section{Declaration of Interest}

This study was self-financed and didn't receive any assistance of any kind by any organization. The authors declare no conflict of interest.

\section{Submission Declaration and Verification}

This work has not been published previously, this is the very first submission. The original collected data are available in a SPSS mask.

\section{Contribution of Authors}

MVE KOH Valere Salomon wrote the manuscript.

NOA NDOUA, DOHBIT SAMA and NANA NJOTANG read and brought inputs to the manuscript.

TEFEE II collected the samples.

LIMITATIONS: the short period of study as long as incidence of anaemia during labor was concerned and the 48 hours short and early post-partum period concerned.

\section{References}

[1] Loebstein, R., Lalkin, A. and Koren, G. (1997) Pharmacokinetic Changes during Pregnancy and Their Clinical Relevance. Clinical Pharmacokinetics, 33, 328-343. https://doi.org/10.2165/00003088-199733050-00002

[2] WHO (2015) The Global Prevalence of Anemia in 2011. World Health Organization, Geneva.

http://apps.who.int/iris/bitstream/handle/10665/177094/9789241564960_eng.pdf;jse ssionid $=6 \mathrm{C} 27 \mathrm{FF} 334832431 \mathrm{C} 1 \mathrm{D} 72532 \mathrm{~A} 072 \mathrm{~A} 3 \mathrm{~F} 24$ ? sequence $=1$

[3] Lumbiganon, P., Laopaiboon, M., Intarut, N., Vogel, J.P., Souza, J.P., Gulmezoglu A.M., et al., WHO Multicountry Survey on Maternal and Newborn Health Research Network (2014) Indirect Causes of Severe Adverse Maternal Outcomes: A Secondary Analysis of the WHO Multicountry Survey on Maternal and Newborn Health. BJOG, 121, 32-39. https://doi.org/10.1111/1471-0528.12647

[4] Achidi, E.A., Kuoh, A.J., Minang, J.T., Ngum, B., Achimbom, B.M., Motaze, S.C., et al. (2005) Malaria Infection in Pregnancy and Its Effects on Haemoglobin Levels in Women from a Malaria Endemic Area of Fako Division, South West Province, Cameroon. Journal of Obstetrics and Gynaecology, 25, 235-240. https://doi.org/10.1080/01443610500060628

[5] Nlinwe, N.O. (2014) Effects of Malaria on Iron Stores in the Pregnant Women of Buea and Tiko Health District, South West Region, Cameroon. Journal of Metabolic Syndrome, 3, 4-9.

[6] Ezzati, M., Lopez, A.D., Rodgers, A.A. and Murray, C.J.L. (2004)ґ Comparative Quantification of Health Risks: Global and Regional Burden of Disease Attributable to Selected Major Risk Factors!' World Health Organization, Geneva. http://www.who.int/iris/handle/10665/42770 
[7] Sukrat, B., Wilasrusmee, C., Siribumrungwong, B., McEvoy, M., Okascharoen, C., Attia, J., et al. (2013) Hemoglobin Concentration and Pregnancy Outcomes: A Systematic Review and Meta-Analysis. BioMed Research International, 2013, 9 p. https://www.ncbi.nlm.nih.gov/pmc/articles/PMC3741929/pdf/BMRI2013-769057.p df

[8] Frass, K.A. (2015) Postpartum Hemorrhage Is Related to the Hemoglobin Levels at Labor: Observational Study. Alexandria Journal of Medicine, 51, 333-337

[9] Maswime, S. and Buchmann, E. (2017) A Systematc Review of Maternal Near Miss and Mortality Due to Postpartum Hemorrhage. International Journal of Gynecology \& Obstetrics, 137, 1-7. https://doi.org/10.1002/ijgo.12096

[10] Schorn, M.N. (2010) Measurement of Blood Loss: Review of the Literature. Midwifery Womens Health, 55, 20-27. https://doi.org/10.1016/j.jmwh.2009.02.014

[11] Duthie, S.J., Ven, D., Yung, G.L., Guang, D.Z., Chan, S.Y. and Ma, H.K. (1991) Discrepancy between Laboratory Determination and Visual Estimation of Blood Loss during Normal Delivery. European Journal of Obstetrics \& Gynecology and Reproductive Biology, 38, 119-124. https://doi.org/10.1016/0028-2243(91)90188-Q

[12] Lertbunnaphong, T., Lapthanapat, N., Leetheeragul, J., Hakularb, P. and Ownon, A. (2016) Postpartum Blood Loss: Visual Estimation versus Objective Quantifcation with a Novel Birthing Drape. Singapore Medical Journal, 57, 325-328. https://doi.org/10.11622/smedj.2016107

[13] Girault, A., Deneux-Tharaux, C., Sentilhes, L., Maillard, F. and Goffinet, F. (2018) Undiagnosed Abnormal Postpartum Blood Loss: Incidence and Risk Factors. PLoS ONE, 13, e0190845. https://doi.org/10.1371/journal.pone.0190845

[14] Milman, N. (2011) Anemia-Still a Major Health Problem in Many Parts of the World! Annals of Hematology, 90, 369-377. https://doi.org/10.1007/s00277-010-1144-5

[15] Daru, J., Zamora, J., Fernández-Félix, B.M., Vogel, J., Oladapo, O.T., Morisaki, N., et al. (2018) Risk of Maternal Mortality in Women with Severe Anaemia. The Lancet Global Health, 6, e548-e554.

https://www.thelancet.com/pdfs/journals/langlo/PIIS2214-109X(14)70227-X.pdf https://doi.org/10.1016/S2214-109X(18)30078-0

[16] Multiple Indicator Cluster Surveys 5 (MICS) 2014 Cameroon. http://slmp-550-104.slc.westdc.net/ stat54/downloads/2016/MICS5_CMR2014_RA PPORT_FINAL.pdf

[17] Driessen, M., Bouvier-Colle, M.-H., Dupont, C., Khoshnood, B., Rudigoz, R.-C. and Deneux-Tharaux, C. (2011) Postpartum Hemorrhage Resulting from Uterine Atony after Vaginal Delivery: Factors Associated with Severity. Obstetrics \& Gynecology, 117, 21-31. https://doi.org/10.1097/AOG.0b013e318202c845

[18] Piengbulan, Y. and Chalermchockcharoenkit, A. (2014) Prevalence, Associated Factors and Pregnancy Outcomes of Anemia during Intrapartum Period in HIV-Infected Pregnant Women. Thai Journal of Obstetrics and Gynaecology, 22, 143-149.

[19] Adesina, O., Oladokun, A., Akinyemi, O., Akingbola, T., Awolude, O. and Adewole, I. (2011) Risk of Anaemia in HIV Positive Pregnant Women in Ibadan, South West Nigeria. African Journal of Medicine and Medical Sciences, 40, 67-73.

[20] Ononge, S., Mirembe, F., Wandabwa, J. and Oona, M.R. (2016) Campbell3 Incidence and Risk Factors for Postpartum Hemorrhage in Uganda Reproductive Health. Reproductive Health, 13, 38-44.

[21] Jatti, G.M., Jadhav, S.B., Behere, V.S., Patil, C.G. and Nandimath, V.A. (2012) 
Missed Opportunities of Anemia Treatment among Pregnant Women Attending Labour Room in a Tertiary Care Hospital of Western Maharashtra. Indian Journal of Maternal and Child Health, 1, 1-7.

[22] Ma, A.G., Schouten, E., Wang, Y., Xu, R.X., Zheng, M.C., Li, Y., Sun, Y.Y., et al. (2009) Anemia Prevalence among Pregnant Women and Birth Weight in Five Areas in China. Medical Principles and Practice, 18, 368-372. https://doi.org/10.1159/000226290

[23] Chen, C. Nutritional Status of Pregnant Women in China. 112th Abbott Nutrition Research Conference Pregnancy Nutrition and Later Health Outcomes. http://static.abbottnutrition.com/cms-prod/anhi.org/img/Chen_112th\%20ANRC-1 12th\%20Abbott\%20Nutrition\%20Research\%20Conference.pdf

[24] Jutcha, F.D., Ngnimi Hougnia, T.F., Nvogue, N., Noubom, M. and Fomulu, N. (2016) Prevalence of Iron Deficiency Anaemia among Pregnant Women in Yaoundé. Health Sciences and Diseases, 17, 1-4.

[25] Fikir, A. (2017) Prevalence of Anemia and Its Associated Factors among Pregnant Women Receiving Antenatal Care at Aymiba Health Center, Northwest. Ethiopia Journal of Blood Medicine, 8, 35-40. https://doi.org/10.2147/JBM.S134932

[26] Yildiz, Y., Ozgu, E., Unlu, S.B., Salman, B. and Yapar Eyi, E.G. (2013) The Relationship between Third Trimester Maternal Hemoglobin and Birth Weight/Length; Results from the Tertiary Center in Turkey. The Journal of Maternal-Fetal \& Neonatal Medicine, 27, 729-732.

http://ARTICLES\%20EN\%20REDACTION\%202018/ANEMIA/Maternal_anemi\%2 0turquie.pdf

[27] NHS (2014) South West RTC Management of Anaemia in Pregnancy. http://ARTICLES\%20EN\%20REDACTION\%202018/ANEMIA/rtc-sw_2014_10_P_ anaemia_in_pregnancy_guideline.pdf

[28] Shilpa, A.S., Raithatha, N.S. and Bhattacharjee, R.S. (2018) Severe Anemia in Late Pregnancy: A Retrospective Study at a Tertiary Care Rural Medical College in Gujarat, India. International Journal of Reproduction, Contraception, Obstetrics and Gynecology, 7, 1112-1115. https://doi.org/10.18203/2320-1770.ijrcog20180903

[29] WHO (2011) Haemoglobin Concentrations for the Diagnosis of Anaemia and Assessment of Severity. Vitamin and Mineral Nutrition Information System. World Health Organization, Geneva, WHO/NMH/NHD/MNM/11.1.

http://www.who.int/vmnis/indicators/haemoglobin.pdf

[30] Lamberta, V., Pougeta, K., Basurkob, C., Boukharic, R., Dallaha, F. and Carle, G. (2013) Geophagy and Pregnancy: Current Knowledge and Management. Clinical Experiences of an Obstetrical Department in French Guiana. Journal de Gynécologie Obstétrique et Biologie de la Reproduction, 43, 496-503.

https://doi.org/10.1016/j.jgyn.2013.06.001

[31] Carroli, G., Cuesta, C., Abalos, E. and Gulmezoglu, A.M. (2008) Epidemiology of Postpartum Haemorrhage: A Systematic Review. Best Practice \& Research: Clinical Obstetrics \& Gynaecology, 22, 999-1012. https://doi.org/10.1016/j.bpobgyn.2008.08.004

[32] Kavle, J.A., Stoltzfus, R.J., Witter, F., Tielsch, J.M., Khalfan, S.S. and Caulfield, L.E. (2008) Association between Anaemia during Pregnancy and Blood Loss at and after Delivery among Women with Vaginal Births in Pemba Island, Zanzibar, Tanzania. Journal of Health, Population and Nutrition, 26, 232-240.

[33] ACOG Committee on Practice Bulletins (2017) ACOG Practice Bulletin. Clinical Management Guidelines for Obstetrician-Gynecologists Number 183 October. 
http://clinicalinnovations.com/wpcontent/uploads/2017/10/ACOG_Practice_Bulleti n_No_183_Postpartum-Hemorrhage-2017.pdf

[34] Contribution à l'amélioration de la qualité de la consultation prénatale: Le cas d'un centre de santé rural, Thiadiaye, département de M’Bour région de Thiès, (Sénégal). Mémoire pour l'obtention du diplôme de 3eme cycle de gestion des programmes de santé, 2008. Centre Africain D’etudes Superieures en Gestion. 111 p.

http://indexmedicus.afro.who.int/iah/fulltext/Theses/Cont_amel_qualConsultPrena t.pdf

[35] AWHONN (2014) Quantification of Blood Loss: AWHONN Practice Brief Number 1. JOGNN, 1-3. https://pdfs.semanticscholar.org/386d/5af1d2b7ffc59797316964219dc1cef306be.pdf

[36] Oishi, T., Tamura, T. and Yamamoto, U. (2017) Outcomes of Blood Losspost Physiological Birth with Physiological Management in the Third Stage of Labour at a Maternity Home in Japan. New Zealand College of Midwives Journal, 53, 23-29.

[37] Gabrielloni, M.C., Armellini, C.J., Barbieri, M. and Schirmer, J. (2014) Analysis of Hemorrhage at Vaginal Delivery by Erythrocyte and Haematocrit Indices. Acta Paulista de Enfermagem, 27, 186-193. https://doi.org/10.1590/1982-0194201400032

[38] Charafeddine, N., Picone, O., Bony, E., Dreyfuss, J.F., Zraik-Ayoubi, F. and Ayoubi, J.M. (2013) Advantage of Systematic Blood Cell Count 2 Days Post-Delivery for the Diagnosis of Postpartum Maternal Anaemia. British Journal of Medicine \& Medical Research, 3, 1144-1153.

[39] Maguire, J.L., Salehi, L., Birken, C.S., Carsley, S., Mamdani, M., Thorpe, K.E., et al. (2013) Association between Total Duration of Breastfeeding and Iron Deficiency.

Pediatrics, 131, e1530-e1537. https://doi.org/10.1542/peds.2012-2465

https://www.ncbi.nlm.nih.gov/pubmed/23589818

[40] Bergmann, R.L., Richter, R., Bergmann, K.E. and Dudenhausen, J.W. (2010) Prevalence and Risk Factors for Early Postpartum Anemia. European Journal of Obstetrics, Gynecology and Reproductive Biology, 150, 126-131. https://doi.org/10.1016/j.ejogrb.2010.02.030

[41] Milman, N. (2011) Postpartum Anaemia: Definition, Prevalence, Causes and Consequences. Annals of Hematology, 90, 1247-1253. https://doi.org/10.1007/s00277-011-1279-z

[42] Barroso, F., Allard, S., Kahan, B.C., Connolly, C., Smethurst, H., Choo, L., et al. (2011) Prevalence of Maternal Anaemia and Its Predictors: A Multi-Centre Study. European Journal of Obstetrics, Gynecology and Reproductive Biology, 159, 99-105. https://doi.org/10.1016/j.ejogrb.2011.07.041

[43] Bhagwan, D., Kumar, A., Rao, C.R. and Kamath, A. (2016) Prevalence of Anaemia among Postnatal Mothers in Coastal Karnataka. Journal of Clinical and Diagnostic Research, 10, 17-20.

[44] Dar, S., Vardi, I.S., Holcberg, G., Reuveni, H., Yerushalmi, R., Katz, M. and Sheiner, E. (2006) Do We Need Routine Complete Blood Count Following Vaginal Delivery? International Journal of Fertility and Women's Medicine, 51, 270-273. 